support these patients with dual needs, three common themes were highlighted: i) $100 \%$ wanted education in this area ii) Stigma found both in mental health and palliative care iii) Not understanding services provided by the other discipline.

Such a need for education has previously been emphasised (Addington-Hall, 2000). There is also a call for increased collaboration in this area (Care Quality Commission, 2016).

Aim A study day was created with the purpose to bring both disciplines together to learn from each other.

Method A proposal was brought to our hospice consortium covering five hospices. Funding was sought and granted. Four bespoke study days were created with the aim of delivering these across the county. Support agreed from the mental health team to educate on the day. Fifteen mental health professionals and 15 palliative care professionals attended the study day. The day was planned to create break-out sessions for each discipline to learn the theory behind practice of the other discipline. Two separate sessions brought the groups together to learn from each other. A pharmacist gave a separate session on medication use for patients with dual needs.

Conclusion We are working towards professionals improving collaboration and ensuring we are prepared to care for all patients. Such education helps reduce the fear and stigma created when caring for such patients (Ellison, 2008). One study day has been delivered with more in October and November. This day has been well evaluated and the consensus on the day was that having both disciplines together created valuable learning and increased awareness of the importance of collaboration when supporting patients.

\section{P-250 END OF LIFE EDUCATION FOR THE EAST OF ENGLAND PARAMEDIC SERVICE - A COLLABORATIVE APPROACH}

Imelda Hodgkinson, Christine Aylott, Caroline Vince, Ramesh Thulavavenkateswaran, Coral Allen, Felicity Callely. St Helena Hospice, Colchester, UK

\subsection{6/bmjspcare-2018-hospiceabs. 275}

Background The opportunity arose to develop and facilitate end of life education to the paramedic service within the regional locality in response to the specific learning needs identified by the service and as part of a commissioning commitment.

Aim The purpose of providing this education was to share specialist palliative care knowledge to improve the care and support offered to those patients and their families who utilise the paramedic service, across the region. This unified approach promotes the quality of person-centred care provision and increased confidence within the paramedic service staff with the emphasis on a shared vision to enhance seamless end of life care.

Method The curriculum that was developed and delivered focused on the agenda of the learners. The education was delivered during three evening workshops over a period of three months by a combination of specialist hospice staff. The topics covered included:

- Recognition of the dying process and communication

- Advance care planning including resuscitation discussions

- Symptom control issues and the role of the out of hours service.
Results The workshops were delivered through some elements of didactic presentation, interactive group discussion and examples of case studies that were provided by the paramedics themselves from past experience with the focus on experiential learning with a high uptake. To date, two workshops have been delivered and with a total of 40 staff participating.

Conclusion As a consequence of this education, the feedback thus far has been of a positive and enquiring manner with a yearning to continue to address further learning needs. Further analysis is required following delivery of the final workshop in July 2018. An early outcome from this initiative is the commitment to deliver yearly workshops between both specialities to promote a more cohesive approach in working cross discipline to enhance the quality of end of life care.

\section{P-251 THE CHALLENGES OF DELIVERING MANDATORY END- OF-LIFE CARE TRAINING TO A MULTI-PROFESSIONAL TEAM}

Sarah Griffiths, Elaine Watson. Stockport NHS Foundation Trust, Stockport, UK

10.1136/bmjspcare-2018-hospiceabs.276

Background In line with national recommendations (Leadership Alliance for the Care of Dying People, 2014; National Institute for Health and Care Excellence, 2015), the Palliative Care Team in Stockport were tasked to provide mandatory training for all frontline staff with responsibility of caring for people in the last two weeks of life. We are keen to share lessons learnt.

Aims Training was: accessible to all acute trust staff every three years; to be included in each member of staff's compliance matrix; multidisciplinary; focused on empathy and compassion: individualising care at the very end of life.

Methods Three sessions available.

- Three hour session for all front line staff dealing regularly with death and dying. This was delivered once a month

- One hour session for those staff not directly involved in care of the dying person

- One hour session for consultant staff not directly involved with care for the dying person.

Each session aimed to:

- Promote discussion on a good death utilising the experience of all grades of health care professionals.

- Use a mixture of group work, discussion, video

- Promote a team approach to decision making.

Results Numbers trained in 2017=547 (49 consultants, 265 nurses, 130 health care assistants, 38 clinical nurse specialists, 40 district nurses and 25 allied health care professionals).

Lessons to share Scepticism was palpable from the group at the beginning of each session but at the end the evaluations were overwhelmingly positive. Getting the training on the compliance matrix was instrumental for attendance at the session. Training a mixed group of health care professionals requires experienced facilitators but can be very rewarding to all. Requests for further training result from every session and the opportunities for supplementary sessions need to be considered. There is a significant impact on workload to the Palliative Care Team who deliver training. 